\title{
A Study on the Influencing Factors of Chinese Family Business's Succession from the Perspective of Re- creation
}

\author{
Li Qi ${ }^{1, *}$ Ratih Hurriyati ${ }^{2}$ Disman ${ }^{3,}$ Mohammad $\mathrm{Ali}^{4}$ \\ ${ }^{1}$ Universitas Pendidikan Indonesia \\ ${ }^{2}$ Universitas Pendidikan Indonesia \\ ${ }^{3}$ Universitas Pendidikan Indonesia \\ ${ }^{4}$ Universitas Pendidikan Indonesia \\ *Corresponding author.Email: liqi@nuit.edu.cn
}

\begin{abstract}
Family business plays an essential role in the world economy, which exists widely both in developed countries and developing countries. For the family business, the successor means the future development direction and growth trend of the business. The inter-generational succession of the family business is a multistage evolution process influenced by many factors. Based on the succession model and characteristics of Chinese family business, this paper analyzes the influencing factors of an inter-generational succession of family businesses from the perspective of re-creation, and systematically classifies the influencing factors into five aspects: creators, successors, relationship, organization, and environment. It provides a reference for the next empirical research on the influencing factors of Chinese family business succession.
\end{abstract}

Keywords: Family Business, Influencing Factors, Succession, Re-Creation .

\section{INTRODUCTION}

\section{1The succession mode and characteristics of chinese family business}

The inter-generational succession of family business is not only the superficial transfer of positions, but it also the transfers of ownership, management and control. It becomes a continuation of resources such as family business, entrepreneurship and interpersonal network. The family business is a special type of spirit, existence, and belief for the creators. It is not only a place for product study, but it is also a special form of their spirit, life, and belief. As a result, intergenerational succession has a greater significance in this regard. Faced with the challenges in the complex and severe international economic and political situation, rising domestic costs and downward pressure on the economy, the key to whether the creator has been able to hold the country for a lifetime is the suitability of the successor. Affected by the traditional "home" culture, the creators of most family businesses in China tend to "follow the father's business." However, there are many creators that have begun to emancipate their minds, put aside the old idea of "no outsider", and try to find suitable successors from a broader range of immediate children, relatives, and friends, subordinate employees and professional managers to open up a new way to hand over the baton of the family business today.

\section{2The mode of "follow the father's business" in chinese traditional culture}

In China, the "home” culture based on blood relatives has deeply rooted. Family is often the axis of all social relations, and family responsibility is more important than any other responsibility. The influence of traditional culture on family business is as follows: the distance between interpersonal relationships is defined by blood and kinship; the creator as a parent has absolute management and decision-making power; family members lack the trust of outsiders and so on. The choice of successor determines the rising and falling of the family business. To maintain and promote the balance between family, business, and the long-term development of family business, the creator will 
instinctively take blood relationship rather than ability as the selection criteria.

Based on the traditional culture, the mode of "follow the father's business" has the following characteristics: firstly, the father has a comprehensive understanding of the children's information, which can effectively reduce the information cost and transaction cost; secondly, the children of entrepreneurs are extremely loyal to the family business. Family members and employees have a high degree of trust in their successors, which helps to reduce the credit cost and promote the stable development of the family and the business. Finally, the children have a clear understanding of the family's vision and the current situation of the enterprise, which can promote the implementation of long-term development strategy and ensure the consistency and continuity of strategy implementation. However, it also has some defects: successors are relatively lacking of entrepreneurial spirit, rich management experience and hard-working character, so it is easy to happen "talent atrophy phenomenon"; When creators have multiple children, they fight over the distribution of ownership and control, leading to family conflicts. As a result of the succession mode based on non-commercial values, Nonfamily members are likely to feel unfairly handled, and employee turnover will grow. Because of feminism's closed trust structure, there must be a barrier to human resources that prevents the effective use of external human capital and management resources. From the perspective of "paratrooper", they can't have a deep and comprehensive grasp of enterprise information. Also, with the restriction of senior managers and the exclusion of family members and enterprise employees, even professional managers with strong management ability can hardly achieve success, so they cannot be universally recognized. In another hand, the children of the creator have unique advantages in this aspect. Firstly, the purpose of the parents' hard work is to create a good living environment for themselves and their children and grandchildren. It is natural to have an expectation that the enterprise can be handed down permanently within the family. Secondly, kinship helps entrepreneurs' children get support and recognition from family members, leadership groups, and employees. Thirdly, they have been influenced by family business and operation and management since they were childhood. Thus, they have embedded with rich cultural knowledge and work experience enable them to have an in-depth understanding of enterprise development, industry characteristics, and market competition, so it is naturally easier for them to integrate into the enterprise faster and better. Based on the explanation above, it is necessary for the creators of the family business to choose "follow the father's business". They are widely recognized and practicable ways in succession under the influence of the unique traditional culture, macro-environment, family ethics, and property rights attributes of our country.
Comparing with other succession modes, it is the most stable transition method.

\section{3Internal training mode from the perspective of extensive familyism}

The internal training model includes two sub-models: the internal non-family, known as internal manager model (internal manager model), and the external family member training. Generally, it is a mode of succession adopted when children lack interest or ability in business management. The internal non-family members are very familiar with the production and operation, strategic principles, and corporate culture of the family business, and have the certain operation and management experience, which is conducive to reducing the corresponding training cost, shortening the time to get familiar with the business, and avoiding large-scale personnel changes. At the same time, it also promotes the career development of all employees, fully mobilizes their enthusiasm and initiative to strive for the top, and enhances the cohesion between each other. Although they are not very familiar with the business and need a certain adaptation time, they will put the family interests first and strive to integrate into the family in determining to achieve corporate vision and long-term planning. In addition, they always pay attention to the sustainable development of family business. Internal training to become an important family business succession model is the common thing that owing to the prevalence of family or familyism in social life. People tend to develop a trust system through interpersonal communication's emotional identity, transforming "strangers" into "selfparts," and Chinese society has evolved into an "acquaintance society". The internal model can expand the scope of the selection, actively promote healthy competition between employees and family members, improve the level of strength and increase the vitality of the enterprise. Effectively, it enhances the consistency of all stakeholders within the family and the enterprise and promotes the introduction of human capital, in order to meet the needs of the family business for standardization, specialization, innovation, and modern management. It become a huge popular in Taiwan and abroad, but it is relatively rare in China. The internal manager model is even rarer. It caused by some reasons: Firstly, although there is a certain understanding between the internal manager and the creator, and the corresponding trust relationship is established, under the guidance of the idea that "blood is thicker than water", even if there is no particularly suitable candidate in the family, the creator does not dare to let non-family members take over, and they will not be willing to entrust the business and property to outsiders for management. Secondly, from the perspective of family responsibilities and family relationships, senior leaders and internal managers of family businesses cannot maintain long-lasting cooperative relationships. Thirdly, there are many 
members in the family business who have the ability to take over, so it will cause dissatisfaction among those who have strength but are not selected, resulting in the loss of some human capital. Fourthly, choosing a successor from non-family members within the company cannot bring new ideas and vitality to the enterprise, which will not be conducive to the development and innovation of the family business. Finally, in general, internal managers have management rights, family members have ownership and decision-making power, and the contradiction between the two powers is inevitable. It is easy to cause internal friction and weaken the strength of the family business in addition, there is another point that needs to be taken seriously. If the family business lack of standardized corporate governance structure and mechanism, so the supervision of internal managers are likely to become a mere formality. After many generations of internal managers take over, it is difficult for the company to implement the "family business behavior based on kin selection", so the family management system will eventually become a public enterprise.

\section{4Professional manager mode under modern corporate governance structure}

Drucker believes that in order to achieve effective operation and long-term development, family businesses must retain at least one non-family member among the top leaders of the company. Redding pointed out that when family businesses encounter bottlenecks in development and find it difficult to seek breakthroughs from within, hiring excellent professional managers can bring fresh blood to the company and help the company survive the crisis. From the perspective of competency, external search far exceeds internal training. Because there are more talents in the external market and a wider range of options, the chances of obtaining specialized managers are greatly increased. Generally, in mature family enterprises, due to the continuous expansion of family scale, equity is gradually dispersed within the scope of family members, a certain share of equity will be sold, and the degree of socialization of the enterprise will become more and more obvious. Therefore, the creator will try the succession model of professional managers to meet the requirements of the expansion and development of the enterprise. This pattern emerged caused by the following reasons: Above all, this is the inevitable demand that optimizes administrative structure, perfect modern company system. Firstly, the property right is not clear and closed. If it cannot be properly handled, it will not only cause family division, but also hinder the financing ability and growth of the enterprise. Secondly, patriarchal management. The survival and development of family business depend on the patriarchal management of the creator in many cases. Thirdly, inbreeding, the key positions of enterprises are generally held by family members, which have affected the introduction of talents, technological innovation and institutional reform. In order to solve these problems and promote the sustainable development of family businesses, the socialization process is essential, which requires professional managers to play a role.

In addition, it is an effective way to solve the shortage of human capital. The human capital available within the family is limited. Faced with endless problems and challenges, relying only on internal resources will lead to insufficient supply and fail to meet the needs of enterprise modernization and diversified development. In reality, even if family members are not competent, creators will still put them in key leadership positions, which leads to a shortage of senior management talents, so it is necessary to rely on professional managers to solve this problem.

To introduce professional managers, it is necessary to establish a set of external recruitment mechanism: Family members' exit plan; Restraint and incentive system; Necessary talent reserve plan; A fair and trusting corporate culture; Sound market for managers. However, in China, professional manager mode is still in the stage of trial and exploration, problems and obstacles are everywhere, and it will take a long time to realize the true integration with family business. The lack of industry organization, ethics, value assessment and record files makes it difficult for professional managers to verify and protect their personal credit problems, even if some of the professional ethics of professional managers is bad, because of the lack of corresponding measures "punishment", they are still able to survive in this professional team, which is the direct cause of the bilateral moral often occur.

\section{METHODS}

From the perspective of the life cycle of the enterprise, most of the family businesses in China are in the stage of the first generation of creators, and only a few of enterprises have entered the new and old alternate stages. According to Drucker's point of view, the combination of ownership and management rights is the best way to survive the family business at this stage. This is in line with the fact that the ownership and control of family business in China is not completely separated and the modern enterprise system is not really established. Therefore, during this period, only when forced to, some entrepreneurs will choose professional manager mode. 


\section{RESULTS AND DISCUSSION}

\subsection{The influencing factors of chinese family business's succession}

For family businesses, successors mean the future direction and growth trend of the company. Different candidates will bring different results. Once there are mistakes in decision-making, it may have a fatal impact on the survival and development of the company. Therefore, in the face of the choice of successors, the creators of family businesses need to consider various factors, weigh the pros and cons and make the most correct choices. In order to promote the smooth transition and long-term development of family businesses, scholars from all over the world have begun to explore the influencing factors of successful succession and regard it as the driving force and source of unremitting exploration of the inheritance field.

With the deepening of normative analysis and empirical research, some relatively "mature" variables have been identified one after another, and some variables that have been ignored for a long time have gradually gained attention. This paper will analyze the influencing factors of family business's intergenerational succession from the perspective of recreation.

\subsection{Creator}

\subsubsection{The intention of the creator to leave.}

The creators have invested a lot of money and feelings to family business, and for them, family businesses are part of life. There is no doubt that businesses have an important position in their creators. As a result, we often find that many old entrepreneurs are still active in the first line of business and they are reluctant to leave. As long as physical conditions permit, they will still be active in family business management activities, and continue to control ownership and management rights in their own hands. In addition, they believe that inheritance will bring about the loss of management power, social status and reputation, thus creating anxiety and reluctance to implement the inheritance plan. In the study of the factors of the family business's succession, that creators do not want to let go which frequency is the highest.

\subsubsection{The personality and requirement of the creator.}

Creators are good at empowering and handing over the power of decision-making to successors. This is very important for the cultivation and development of successors' leadership skills, and is also essential for the successful succession of family businesses. However, they often have a sense of mystery and intuition, unaccustomed to authorization, and even some constraints, such as distrust, doing things by themselves. Therefore, it is equally important for creators to have a high degree of trust, positive guidance, good communication and knowledge sharing on the ability and strength of successors.

\subsubsection{Entrepreneurship.}

The culture of a family business is often the spiritual culture of the first generation of creators. The entrepreneurial intention is the original embodiment of the entrepreneurial spirit. The entrepreneurial intention is the fundamental basis and starting point of all entrepreneurial activities. It is also the key to the entrepreneurial spirit. So the succession of entrepreneurial spirit is more important than the succession of ownership and control right. The growth environment and social background of the creator and successor of family business are very different. The two generations of the father and son have different opinions on corporate culture, values and management norms. In China, the first generation of family business leaders are generally low-educated, while most of their generations have a good educational background, so they have a systematic and in-depth understanding of new knowledge, new technologies, organizational structure and management models. And vigorously advocate the integration of modern management into the family business, changing the previous empirical management model. However, the succession and continuation of the core culture and management system of the enterprise to a certain extent is of great significance for ensuring the stability and coherence of the enterprise. Finding the point of convergence between culture and system between the two generations of father and son means that the creator can really decentralize and hand over the enterprise to the successor.

\subsection{Successor}

\subsubsection{The aspiration of the successor.}

"Follow the father's business" is often the preferred succession model for family businesses, and it is also a necessary prerequisite for the business to continue to succeed in the form of family businesses. Therefore, the succession interest and willingness of the children of entrepreneurs have a great influence on whether this problem can be effectively solved. In China, there is a common phenomenon that children are not willing to take over the family business, and the expected return of the successor on the family business also affects the willingness to take over to some extent. Rewards in terms of work pleasure, honor and material status are favorable factors to attract successors to take over the family business. Material rewards given by parents are the driving force for their children to join the family 
business. The better the opportunities in the family business and the successor's personal career needs, personality, and life cycle, the smoother the succession process. From another perspective, the higher the satisfaction of the successor to the company, the more energy will be invested, the higher the enthusiasm for work, and the stronger the sense of responsibility. At the same time, there will be a unique sense of identity that it is worthy for family business.

\subsubsection{The ability of the successor.}

Most empirical studies have shown that successors' education level, management ability, interpersonal network relationship and moral quality are positively related to smooth succession, and they can help successors to obtain credibility and legitimacy to a large extent. [1]. Believe that the level of education of successors is related to effective succession. King's empirical research found that the potential of successors has a significant impact on corporate performance after three years of succession. Miller pointed out that the lack of competence of successors is the root cause of failure, and strong physical fitness and good psychological quality contribute to successful succession. The development of the successors and the preparation of the leadership role are one of the most important factors influencing the success of the family business. In a study of family businesses that failed in the United States, [2] found that $45 \%$ of the failures of succession were rooted in the inability of the successors to assume leadership roles. Therefore, educating or training the successors to help them acquire knowledge and improve their ability to gain recognition and orthodoxy is an important way and means to promote the success of the family business.

\subsubsection{The preparation of the successor.}

The degree of preparation is mainly related to internal career development and external work experience. Early contact with the business can make the successors more familiar with the company's culture, values and employees, which also cultivate and develop the capabilities required by the business. The internal career development of the enterprise, especially the grassroots work experience, is conducive to strengthening the successor's recognition of the company's core values and family culture, helping the successor to establish a good network of interpersonal relationships, establishing the necessary entrepreneurial prestige, and in heterogeneous resources and the transfer of knowledge has also played an important role. In addition, successors can build relationships and trust through successful job promotion. The work experience of successors starting from the grassroots level and gradually being promoted has a positive impact on the performance after succession. And effective successors have longer family business work experience than ineffective successors. External work experience helps to improve the knowledge reserve, identity and credibility of successors, and accumulate management knowledge and practical experience. None of the successors with external work experience regretted it, and those who did not have external work experience would like to have a similar experience. Family business successors that achieve successful succession have a much richer external work experience than successors of family businesses that fail to succession.

\subsection{Relationship}

\subsubsection{The relationship between creator and successor.}

The inter-generational succession of family business is closely related to the current situation of the relationship between family and business, especially the relationship between creators and successors. The relationship between the two includes mutual trust, Shared vision, cooperation and father-son relationship. Because family business creators have a long time to work, they have a large number of heterogeneity or tacit recognition related to the business. The effectiveness of this cognition and inter-generational transfer of social network has an important impact on the performance of the next generation. Studies by Goldberg have shown that the quality of the relationship between the creator and the successor is significantly positively correlated with the success of the family business. Successors often regard the trust and respect of creators as their recognition and support. The communication between father and son on the world view, outlook on life, values, corporate, etc. is an important way to establish a harmonious relationship between the creators and the successor.

\subsubsection{The relationship between family members.}

Compared with non-family businesses, the pursuit of harmonious family relationships by family members sometimes exceeds the desire for profit. Especially in China, the "home culture" based on "Family harmony makes everything", the harmonious relationship between family members can produce strong centripetal force and cohesion, so that they can work together to solve various problems. Relevant studies have also found that harmonious relationship has a good promotion effect on communication, understanding and trust among family members, which will also have a positive impact on successful succession. The degree of harmony among family members has a significant impact on the smoothness of the succession process. Among that, the relationship between family members includes different dimensions such as the relationship between descendants, the relationship between descendants and predecessors, and the relationship between creator and their spouses. 


\subsubsection{The relationship between successors and non-family members.}

Non-family members include non-family shareholders, middle and senior managers and employees. The inter-generational succession of family business is accompanied by power changes and personnel transfers. This structural change will bring many uncertainties, which are not only related to family members, but also related to non-family members. If the problems arising in the process of change are not handled properly, serious conflicts and contradictions are likely to arise, hindering the smooth progress of succession and even leading to the decline and fall of family businesses. Therefore, successors should not only be recognized by entrepreneurs and other family members, but more importantly, they should be supported by important groups such as entrepreneur veterans, non-family shareholders and enterprise employees.

\subsection{Organization}

\subsubsection{Succession plan.}

The inter-generational succession of family business is a dynamic and complex process. As an important rule and guarantee of this process, the succession plan plays a key role in the success of succession. Most young family businesses rely too much on the knowledge, experience and relationships of the first generation of creators, and the absence of succession plans leads to the loss of these important intangible management resources. Given the complexity of the family business's inter-generational succession process, pre-planned management is critical to the success of the business. Especially in the case of the sudden death of the creator, such absence will largely lead to the upheaval of power structure, which will intensify the conflicts between the children of entrepreneurs and other family members, and cause problems in strategic decision-making and finance. Family businesses that have established succession plans and communicated with key stakeholder groups are more profitable than those that do not have a plan. In reality, the vast majority of family businesses that make succession plans do not treat it as an important strategic decision, which is also the direct reason for frequent failures in succession.

\subsubsection{Common vision.}

Common vision is the third discipline mentioned by [3]. He believes that the common vision of a team can help an organization cultivate the initiative and sincere dedication and devotion of its members. Having a highly consistent common vision and working together towards this ultimate goal have actively promoted the realization of the successful succession. Lansberg believes that the vision of the future of the company is the driving force in the succession process, which effectively matches the wishes of generations and plays an important role in attracting children to the family business. [4] stressed that, in order to achieve successful succession, the family must have a fair and Shared view. They must form "highlevel goal" that everyone agrees on and strives for. Goals that bind the family together. If the common vision of the successor and the family business is highly consistent, it will be easier to get the recognition and support of the creator, entrepreneur veterans and employees of the enterprise, which is conducive to the realization of successful succession. The establishment and persistence of the common vision is the driving force for the healthy and rapid development of family businesses and is conducive to improving the success rate of succession.

\subsubsection{Board of directors.}

From the perspective of law, the protection of the legitimate rights and interests of shareholders is the responsibility of the board of directors. For the family business, the board of directors plays a broader role in both the family and business systems. Many scholars emphasized the importance of the board of directors, they believe that a well-designed, clear responsibilities, including external independent directors of the board, can help the creators overcome the psychological obstacles in the process of succession and guide the smooth implementation of the succession plan. It is also possible to supervise the entire handover process in real time and, if necessary, to use the rights and obligations to enforce the succession plan to protect the owner's rights. In addition, the board of directors can provide suggestions to the management toresolve various contradictions and conflicts in the process of succession and ensure a smooth transition.

At the same time, in Chinese Family businesses, the role of the Family council is not prominent enough. Even some Family businesses have not set up a Family council, which is often replaced by some other organizational forms. Therefore, it will not be discussed as a separate influencing factor

\subsection{Environment}

\subsubsection{Re-creation stage.}

Under the background of great changes in China's economic environment, a large number of small and medium-sized family businesses are in urgent need of transformation and upgrading and entering the channel of re-creation. Re-creation is no longer for survival, but for an ecological creation. Establishing a modern knowledge industry and carrying out scientific knowledge operations are the core links of re-creation. And that can help to cultivate entrepreneurship of successors. Entrepreneurship is one of the scarcest resources of 
family business. The realization of inter-generational transmission of entrepreneurship is directly related to the success or failure of family business.

Creators sets up an example for their successors to start a business through the process of re-creation, and sends them a message full of crisis. At the same time, it is also possible to set an example for other elders in family business through the gradual decentralization of the process of re-creation, so that they also realize that it is time for the business to let new leaders take over, reducing the psychological impact of the real implementation stage and winning wider support.

The way of succession by re-creation is a precautionary move. Through the process, the power transfer is gradual and smooth. Especially for the second generation successors, re-creation is both a crisis challenge and a success opportunity, and it requires successors to complete the mission successfully through "creative succession". So the succession of entrepreneurial spirit is more important than the succession of ownership and control right

\subsubsection{Industry background.}

The degree of competition varies according to the industry in which the family business is located, and the abilities and qualities of the successors may vary. Industries with less competitive intensity have lower requirements for successors, so creators, successors and other family members have enough time to adapt to changes in roles, and the probability of successful succession increases. Industries with higher competition intensity also have higher requirements on the ability of successors. Once the corresponding standards are not met, it is likely to fail in succession and even hinder the long-term development of enterprises.

The evolution path of the industry will not only affect the type of leader of the successor of the family business, but also have a certain impact on the training method of the successor. For family businesses in traditional industries, because the industry is stable, the enterprise does not need too much change will be able to adapt to the demand of the development, and career development within the enterprise to a large extent can effectively for a long time, after appropriate training and experience for the next generation of family members the possibility of a qualified leader will also be greatly increased.If family businesses are exposed to rapidly changing markets and have to make frequent adjustments to adapt to a competitive environment, training by a competitive organization or enterprise in the relevant industry may be more effective.

\subsubsection{Society background.}

Family business is deeply rooted in social environment and generations succession is a long process of social. Therefore, family business succession of two generations is bound to be affected by many factors just like the confucian culture, laws and regulations, moral ethics and clan beliefs. So the relationship between blood, kinship, geography and so on becomes the most direct standard for measuring the trust system. For example, in terms of equity allocation, there is hardly any joint ownership by children in American family businesses, but this phenomenon is very common in Asia and Latin America. In the selection criteria of successors, external work experience plays an important role in the selection criteria of family enterprises in the United States, while it is generally not valued in Portugal. Therefore, in the study of inter-generational succession of family businesses, cultural differences are a factor that must be paid attention to.

China is in the transition period, and its economic system is still changing. Laws and regulations on the protection of private property rights, the protection of trade secrets and inheritance tax rates are still not perfect, and the market for professional managers is not perfect, which also makes it difficult for external human capital to become a candidate for succession of family businesses. At present, there is no mature professional manager market in China, and the absence of credit evaluation mechanism and reputation mechanism leads to the widespread moral hazard and trust crisis. In addition, due to the long-term adoption of family management in enterprises, there is a lack of incentive and restraint system for professional managers, which is also the direct cause of conflicts and disputes between business owners and professional managers. China's special "family culture", economic environment, moral norms and legal environment, will inevitably have a direct or indirect impact on the inter-generational succession of family businesses.

\section{CONCLUSIONS}

In combination with practice, appropriate comprehensive selection is made among the numerous influencing factors. Finally, five factors are proposed as a discussion aspect to analyze the influence of these factors on the succession of Chinese family businesses. According to the content of each factor and its influence way, subdivide a number of indicators to measure. As follows:

Creator (The intention of the creator to leave, The personality and requirement of the creator, Entrepreneurship); 
Successor (The aspiration of the successor, The ability of the successor, The preparation of the successor);

Relationship (The relationship between creator and successor, The relationship between family members, The relationship between successors and non-family members);

Organization (Succession plan, Common vision, Board of directors)

\section{REFERENCES}

[1] S. D. Goldberg, "Research note: Effective successors in family-owned businesses: Significant elements," Fam. Bus. Rev., vol. 9, no. 2, pp. 185197, 1996.

[2] I. Le Breton-Miller, D. Miller, and L. P. Steier, "Toward an integrative model of effective FOB succession," Entrep. Theory Pract., vol. 29, no. 2, pp. 305-328, 2004.

[3] P.M. Senge, The fifth discipline: the art \& practice of the learning organization. USA: Doubleday. Random House, Inc. 1990.

[4] W.G. Dyer and M. Sánchez, "Current state of family business theory and practice as reflected in family business review 1988-1997," Fam. Bus. Rev., vol. 11, no. 4, pp. 287-295,1998.

[5] P. Sharma, "An overview of the field of family business studies: current status and directions for the future," Fam. Bus. Rev., vol. 17, no. 1, pp. 1-36, 2004

[6] J.A. Barach, and J.B. Ganitsky, J.B "Successful succession in family business," FamilyBusiness Review., vol. 8, no. 2, pp. 131-155, 1995.

[7] P. Sharma, J.J. Chrisman, and J.H. Chua, "Succession planning as planned behavior: some empirical results," Fam. Bus. Rev., vol. 16, no. 1, pp. 1-16, 2003.

[8] W.C. Handler, "The succession experience of the next generation," Fam. Bus. Rev., vol. 5, no. 3, pp. 283-307, 1992.

[9] M.H. Morris, R.O. Williams, J.A. Allen, and R.A. Avila, "Correlates of success in family business transitions," J. Bus. Ventur., vol. 12, no. 5, pp. 285401, 1997.

[10] M.K. Fiegener, B.M. Brown, R.A. Prince, and K.M. File, "Passing on strategic vision," J. Small Bus. Manag., vol. 34, no. 3, pp. 15-26, 1996.

[11] K.S. Lee, G.H. Lim, and W.S. Lim, "Family business succession: Appropriation risk and choice of successor," Acad. Manag. Rev., vol. 18, no. 4, pp. 657-666, 2003.

[12]E. Venter, C. Boshoff, and G. Maas, "The influence of successor-related factors on the succession process in small and medium-sized family businesses," Fam. Bus. Rev., vol. 18, no. 4, pp. 283 303, 2005.

[13]W.L. Martin and G.T.Lumpkin, "From entrepreneurial orientation to 'family orientation': generational differences in the management of family businesses," Babson Coll., pp. 309-321, 2004.

[14]S.A. Zahra, "International expansion of U.S. manufacturing family businesses: The effect of ownership and involvement," J. Bus. Ventur., vol. 4, pp. 495-512, 2003.

[15] J.V. Hofmann, "family mindset as predictor of entrepreneurship in german family firms," $\mathrm{Ph} . \mathrm{D}$. thesis, 2009.

[16] E. McCann, A.Y. Leon-Guerrero, and J.D. Haley, "Strategic goals and practices of innovative family businesses,” J. Small Bus. Manag., pp. 50-59, 2001.

[17] S. Klein and F. Bell, "Non-family executives in family businesses: A literature review," J. Fam. Bus. Stud., pp. 19-37, 2007.

[18] T.S. Feltham, G. Feltham, and J.J. Barnett, "The dependence of family businesses on a single decision-maker," J. Small Business Management., pp. 1-15, 2005.

[19]A. Srivastava and H. Lee, "Predicting order and timing of new product moves: The role of top management in corporate entrepreneurship," J. Bus. Ventur., pp. 459-481, 2005.

[20]S.A. Zahra, J.C. Hayton, and C. Salvato, "Entrepreneurship in family vs. non-family firms: A resource-based analysis of the effect of organizational culture," Entrep. Theory Pract., pp. 363-381, 2004.

[21] J.G. Covin and D.P. Slevin, "A conceptual model of entrepreneurship as firm behavior," Entrep. Theory Pract., 1991.

[22] J. Barney, "Firm resources and sustained competitive advantage," J. Manage., 1991. 